Die französische Heine-Kritik

Band 1: 1830-1834 


\section{Heine-Studien}

Herausgegeben von Joseph A. Kruse

Heinrich-Heine-Institut der Landeshauptstadt Düsseldorf 


\title{
Die französische Heine-Kritik
}

\author{
Band 1: \\ Rezensionen und Notizen zu Heines Werken \\ aus den Jahren 1830-1834
}

Herausgegeben von Hans Hörling

Verlag J. B. Metzler

Stuttgart - Weimar 
Die Deutsche Bibliothek - CIP-Einheitsaufnahme

Die französische Heine-Kritik / hrsg. von Hans Hörling.

- Stuttgart; Weimar : Metzler

(Heine-Studien)

NE: Hơrling, Hans [Hrsg.]

Bd. 1. Rezensionen und Notizen zu Heines Werken aus den Jahren 1830-1834. - 1996

ISBN 978-3-476-01320-0

ISBN 978-3-476-01320-0

ISBN 978-3-476-03608-7 (eBook)

DOI 10.1007/978-3-476-03608-7

Dieses Werk einschließlich aller seiner Teile ist urheberrechtlich geschutzt. Jede Verwertung auBerhalb der engen Grenzen des Urheberrechtsgesetzes ist ohne Zustimmung des Verlages unzulassig und strafbar.

Das gilt insbesondere fur Vervielfaltigungen, Übersetzungen, Mikroverfilmungen und die Einspeicherung und Verarbeitung in elektronischen Systemen.

(C) 1996 Springer-Verlag GmbH Deutschland

Ursprünglich erschienen bei J. B. Metzlersche Verlagsbuchhandlung und Carl Emst Poeschel Verlag GmbH in Stuttgart 1996 